Article

\title{
Resistance to Cleavage of Core-Shell Rubber/Epoxy Composite Foam Adhesive under Impact Wedge-Peel Condition for Automobile Structural Adhesive
}

\author{
Jong-Ho Back ${ }^{1}{ }^{\oplus}$, Dooyoung Baek ${ }^{1,2}{ }^{\mathbb{D}}$, Jae-Ho Shin ${ }^{1}$, Seong-Wook Jang ${ }^{1,2}$, \\ Hyun-Joong Kim ${ }^{1,2, *}$, Jong-Hak Kim ${ }^{3}$, Hong-Kyu Song ${ }^{3}$, Jong-Won Hwang ${ }^{4}$ and Min-Jae Yoo 5 \\ 1 Laboratory of Adhesion and Bio-Composites, Program in Environmental Materials Science, College of \\ Agriculture and Life Science, Seoul National University, Seoul 08826, Korea; beak1231@snu.ac.kr (J.-H.B.); \\ baek.s.dy@snu.ac.kr (D.B.); pass2462@snu.ac.kr (J.-H.S.); jangsw0202@snu.ac.kr (S.-W.J.) \\ 2 Research Institute of Agriculture and Life Sciences, College of Agriculture and Life Sciences, Seoul National \\ University, Seoul 08826, Korea \\ 3 Unitech Co., Ltd., Byeolmang-ro 459beon-gil 45, Gyeonggi-do 15598, Korea; jh.kim@unitech99.co.kr (J.-H.K.); \\ hongq@unitech99.co.kr (H.-K.S.) \\ 4 Kukdo Chemical Co., Ltd., Gasandigital 2-ro, Seoul 08588, Korea; pac3@kukdo.com \\ $5 \quad$ Korea Research Institute of Chemical Technology, 141 Gajeongro, Daejeon 34114, Korea; yoomin@krict.re.kr \\ * Correspondence: hjokim@snu.ac.kr; Tel.: +82-2-880-4784; Fax: +82-2-873-2318
}

Received: 17 December 2018; Accepted: 14 January 2019; Published: 17 January 2019

\begin{abstract}
Epoxy foam adhesives are widely used for weight reduction, watertight property, and mechanical reinforcement effects. However, epoxy foam adhesives have poor impact resistance at higher expansion ratios. Hence, we prepared an epoxy composite foam adhesive with core-shell rubber (CSR) particles to improve the impact resistance and applied it to automotive structural adhesives. The curing behavior and pore structure were characterized by differential scanning calorimetry (DSC) and X-ray computed tomography (CT), respectively, and impact wedge-peel tests were conducted to quantitatively evaluate the resistance to cleavage of the CSR/epoxy composite foam adhesives under impact. At 5 and $10 \mathrm{phr}$ CSR contents, the pore size and expansion ratio increased sufficiently due to the decrease in curing rate. However, at $20 \mathrm{phr}$ CSR content, the pore size decreased, which might be due to the steric hindrance effect of the CSR particles. Notably, at 0 and $0.1 \mathrm{phr}$ foaming agent contents, the resistance to cleavage of the adhesives under the impact wedge-peel condition significantly improved with increasing CSR content. Thus, the CSR/epoxy composite foam adhesive containing $0.1 \mathrm{phr}$ foaming agent and $20 \mathrm{phr}$ CSR particles showed high impact resistance $\left(E_{\mathrm{C}}=34,000 \mathrm{~mJ} / \mathrm{cm}^{2}\right)$ and sufficient expansion ratio $(\sim 148 \%)$.
\end{abstract}

Keywords: epoxy composite foam adhesive; core-shell rubber; impact wedge-peel test; automobile structural adhesives

\section{Introduction}

An epoxy foam adhesive is an epoxy containing a foaming agent that generates a gas inside the epoxy resin or expands upon heat treatment. After heat treatment, the epoxy foam adhesive is cured and foamed, simultaneously filling the gap between two substrates and binding them [1,2]. Through this process, the epoxy foam adhesive provides weight reduction, watertight property, and reinforcement effects, and can thus be applied to structural adhesives in automobiles [1].

As the mechanical strength of an epoxy foam adhesive weakens through an increase in the expansion ratio [3], it is necessary to improve the mechanical strength while preserving the expansion ratio. Particularly, since the impact resistance of an epoxy foam adhesive is important for its application 
to structural adhesives in automobiles, epoxy composite foam adhesives containing an additive that improves impact resistance are required [4].

Rubber particles have been widely used to enhance the impact resistance of epoxy composites [5-8]. However, the poor dispersion and aggregation of rubber particles in a composite decreases the impact resistance at a high content of rubber particles. Therefore, core-shell rubber (CSR) particles, in which rubber particles form the core structure and a polymer forms the shell, have been developed [9]. Using CSR particles in a composite rather than rubber particles, the dispersion of CSR particles in the composite can be improved and impact resistance can be enhanced [9-11].

The pore structure of epoxy composite foams is typically characterized by two-dimensional analysis, such as scanning electron microscopy (SEM) [3,12-15]. Two-dimensional analysis can be used to observe only the sample surface, and the investigation of the internal pore structure necessitates a destructive evaluation of the epoxy composite foam adhesive. However, $\mathrm{X}$-ray computed tomography (CT) can nondestructively characterize the internal pore structure of polymeric foams $[1,16,17]$ and can quantitatively evaluate the average pore size, standard deviation of pore size, porosity, and expansion ratio.

Further, the impact resistance of an epoxy composite containing CSR particles has been conventionally evaluated by a ballistic impact test [10], izod impact test [11], etc. By contrast, to evaluate the impact resistance of structural adhesives, a test specimen is adhesively bonded and impact is applied to the specimen using instruments such as an Izod impact tester $[4,11,18]$, impact wedge-peel tester $[19,20]$, and servohydraulic tester [21].

In this study, epoxy composite foam adhesives containing epoxy resin, a foaming agent, and CSR particles were prepared, and their pore structure was characterized by X-ray CT. We used an impact wedge-peel tester and their resistance to cleavage of the epoxy composite foam adhesive under impact condition. We investigated the effect of CSR particles on the pore structure and impact resistance of the epoxy composite foam adhesive containing different amounts of foaming agent and suggested an optimal content of CSR particles to achieve a high expansion ratio and impact resistance.

\section{Materials and Methods}

\subsection{Materials}

Two epoxy resins were used to prepare epoxy composite foams: Bisphenol-A diglycidyl epoxy resin (YD-128, Kukdo Chemical Co., Ltd., Seoul, Korea) and urethane-modified epoxy resin (UME, Kukdo Chemical Co., Ltd., Seoul, Korea). A dicyandiamide curing agent (Dyhard 100S, AlzChem, Trostberg, Germany) and a latent accelerator (Dyhard UR500, AlzChem, Trostberg, Germany) were blended with the epoxy resins for curing. The CSR particles were composed of butadiene rubber cores and poly(methyl methacrylate) shells. We used CSR particles (35 wt \%) predispersed in bisphenol-A diglycidyl epoxy resin (KDAD-1760, Kukdo Chemical Co., Ltd., Seoul, Korea). Calcium carbonate $\left(\mathrm{CaCO}_{3}, 10 \mathrm{CN}\right.$, OMYA, Oftringen, Switzerland) and expandable microcell (F-360, Matsumoto Yushi-Seiyaku Co., Ltd., Osaka, Japan) were used as filler and a foaming agent, respectively. Detailed information of the materials employed in this work is presented in Table 1. The foaming mechanism of the expandable microcell and the TEM images of the CSR particles are shown in Figure 1.

Table 1. Materials used for preparing epoxy composite foam adhesive.

\begin{tabular}{cccc}
\hline \multirow{2}{*}{ Materials } & Composition & Abbreviation & $\begin{array}{c}\text { Equivalent Weight } \\
\text { (g/eq) }\end{array}$ \\
\hline \multirow{2}{*}{ Epoxy } & Bisphenol-A diglycidyl epoxy & BPA-E & 187 \\
\cline { 2 - 4 } & Urethane-modified epoxy & UME & 475 \\
\hline \multirow{2}{*}{ Curing agent } & Dicyandiamide & CA-1 & 21 \\
\cline { 2 - 4 } & Substituted urea & CA-2 & 3 \\
\hline CSR + Epoxy & CSR in epoxy resin (35 wt $\%)$ & CSR mixture & 287.7 \\
\hline
\end{tabular}


(a)
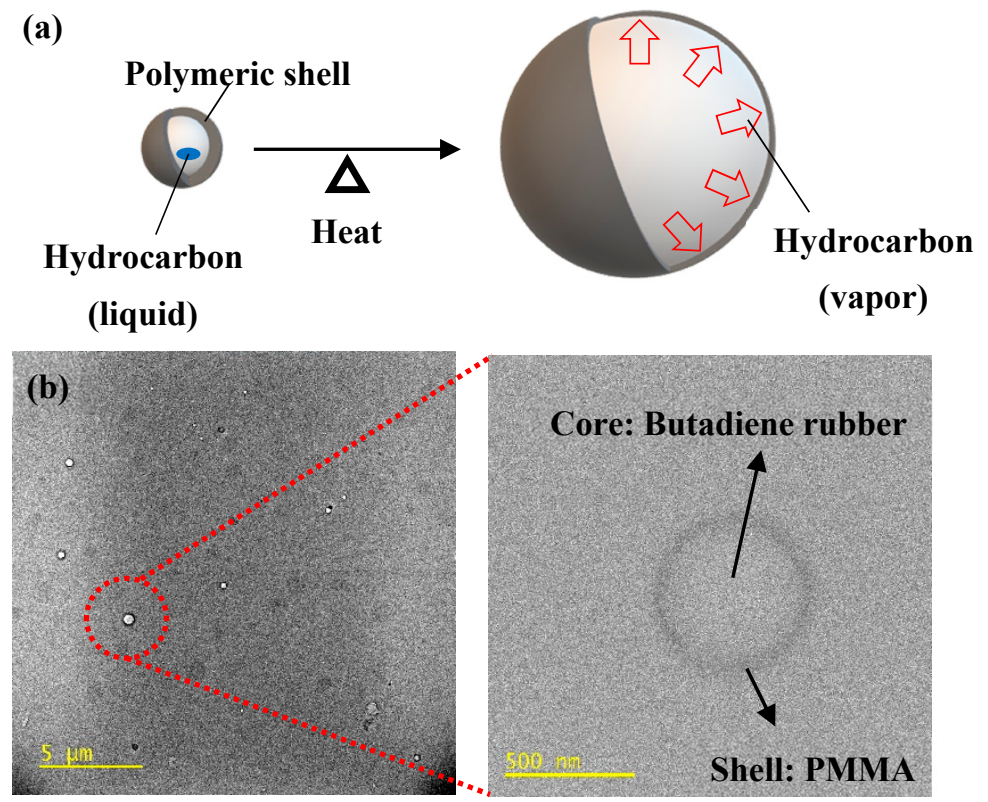

Figure 1. (a) Foaming mechanism of expandable microcell foaming agent and (b) TEM images of core-shell rubber (CSR) particle.

\subsection{Curing and Foaming of CSR/Epoxy Composite Foam Adhesive}

Materials were blended, maintaining the ratio of total equivalent weight of epoxy to curing agents as 1.00 (Table 2). Different amounts of the CSR mixture were blended so that the CSR content in the composites varied as $0,5,10$, and $20 \mathrm{phr}$. Further, $\mathrm{CaCO}_{3}$ was added so that the total weight of CSR particles and $\mathrm{CaCO}_{3}$ was 20 phr. Moreover, the foaming agent content in the samples was varied as 0 , 0.1 , and $1 \mathrm{phr}$. All the samples were cured and foamed at $170{ }^{\circ} \mathrm{C}$ for $40 \mathrm{~min}$.

Table 2. Composition of epoxy composites.

\begin{tabular}{ccccc}
\hline Sample & BPA-E $(\mathbf{g})$ & CSR Mixture $(\mathbf{g})$ & $\mathrm{CaCO}_{\mathbf{3}} \mathbf{( g )}$ & Foaming Agent $(\mathbf{g})$ \\
\hline CSR 0/FA 0 & 14.96 & 0 & 6.03 & 0 \\
\hline CSR 5/FA 0 & 12.16 & 4.31 & 4.52 & 0 \\
\hline CSR 10/FA 0 & 9.36 & 8.62 & 3.02 & 0 \\
\hline CSR 20/FA 0 & 3.76 & 17.23 & 0 & 0 \\
\hline CSR 0/FA 0.1 & 14.96 & 0 & 6.03 & 0.032 \\
\hline CSR 5/FA 0.1 & 12.16 & 4.31 & 4.52 & 0.032 \\
\hline CSR 10/FA 0.1 & 9.36 & 8.62 & 3.02 & 0.032 \\
\hline CSR 20/FA 0.1 & 3.76 & 17.23 & 0 & 0.032 \\
\hline CSR 0/FA 1 & 14.96 & 0 & 6.03 & 0.32 \\
\hline CSR 5/FA 1 & 12.16 & 4.31 & 4.52 & 0.32 \\
\hline CSR 10/FA 1 & 9.36 & 8.62 & 0 & 0.32 \\
\hline CSR 20/FA 1 & 3.76 & 17.23 & 0.32 \\
\hline
\end{tabular}

* Contents of urethane-modified epoxy resin (UME), CA-1, and CA-2 were set as 15.20, 1.51, and $0.12 \mathrm{~g}$, respectively. 


\subsection{Differential Scanning Calorimetry (DSC)}

DSC (DSC Q200, TA Instruments-Waters Korea Ltd., Seoul, Korea) was performed to compare the curing behaviors of the epoxy composite foams. The heat flow of exothermic curing reaction was measured during the DSC run in the temperature range of $60-240{ }^{\circ} \mathrm{C}$ at a constant heating rate of $5{ }^{\circ} \mathrm{C} / \mathrm{min}$.

\subsection{X-ray Computed Tomography}

The pore structure was characterized by X-ray CT (Skyscan 1272, Bruker Korea Co., Ltd., Gyeonggi-do, Belgium). The X-ray head $(50 \mathrm{kV})$ was rotated around the epoxy composite foam and tomographic images were captured every $0.6^{\circ}$. These tomographic images were collected and converted into 3D images. The average pore size, standard deviation of pore size, and porosity were evaluated by the software (CT Analyzer, Bruker Korea CO., Ltd., Gyeonggi-do, Belgium), and the expansion ratio was calculated by Equation (1).

$$
\text { Expansion ratio }(\%)=\frac{V_{\text {total }}}{V_{\text {total }}-V_{\text {pore }}} \times 100=\frac{100}{100-\text { porosity }(\%)} \times 100,
$$

where $V_{\text {pore }}$ and $V_{\text {total }}$ represent the total volume of pores and the measured region, respectively.

\subsection{Impact Wedge-Peel Test}

An impact wedge-peel test was performed according to ISO 11343 standard to compare the resistance to cleavage of the CSR/epoxy composite foam adhesives under impact using a drop weight tester (Dyntaup ${ }^{\circledR M o d e l} 9250 \mathrm{HV}$, Instron, Norwood, MA, USA). Specimens for the impact wedge-peel test were prepared as shown in Figure 2. Two bent steel plates (length: $90 \mathrm{~mm}$, width: $20 \mathrm{~mm}$, thickness: $1.6 \mathrm{~mm}$, material: CR340) were bonded using the CSR/epoxy foam composite adhesive (area: $20 \times 20 \mathrm{~mm}^{2}$, thickness: $0.2 \mathrm{~mm}$ ), and the force was measured when the adhesive layer was cleaved by the wedge at a velocity $(v)$ of $2.0 \mathrm{~m} / \mathrm{s}$.

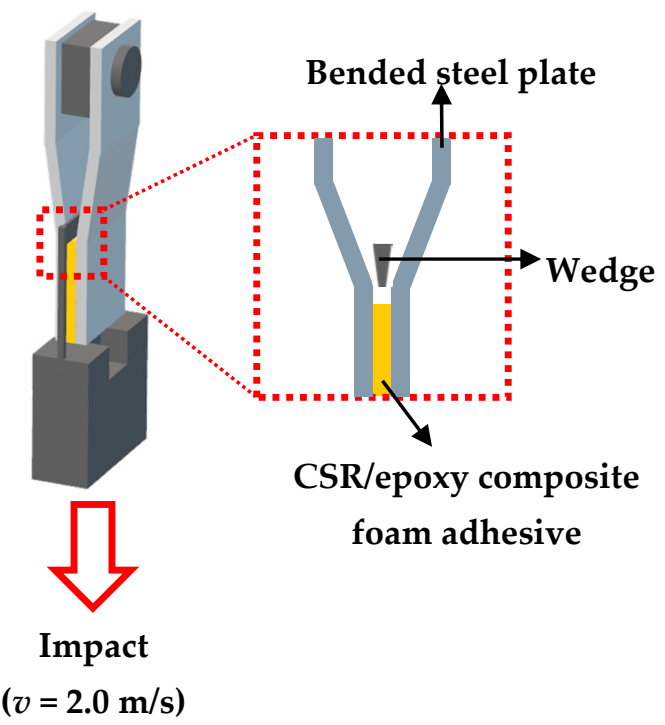

Figure 2. Schematic illustration of specimen prepared for impact wedge-peel test. 
As shown in Figure 3, a force-time curve can be obtained by the impact wedge-peel test. According to the shape of the curve, crack growth can be classified into two types: Stable and unstable crack growth. While stable crack growth has a constant region of cleavage force, for unstable crack growth, cleavage occurred in an instant without a constant region of force (Figure 3a,b, respectively). The area of the force-time curve is proportional to the energy of crack growth $\left(E_{C}\right)$, which quantitatively represents the impact resistance. Displacement for cleavage $\left(D_{C}\right)$ is determined by the displacement at the finish point of the cleavage.

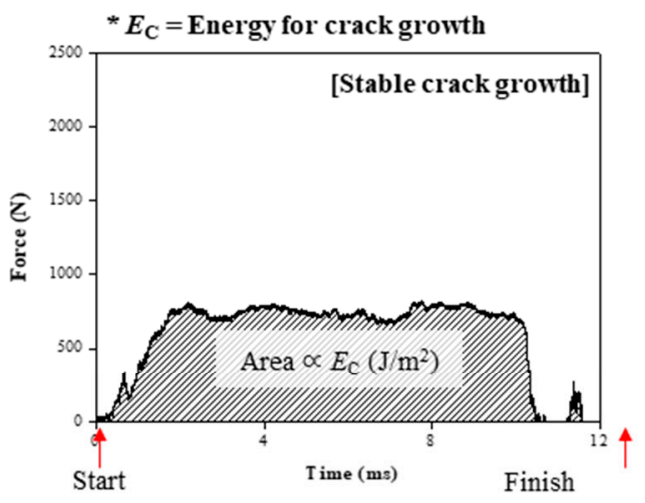

(a)

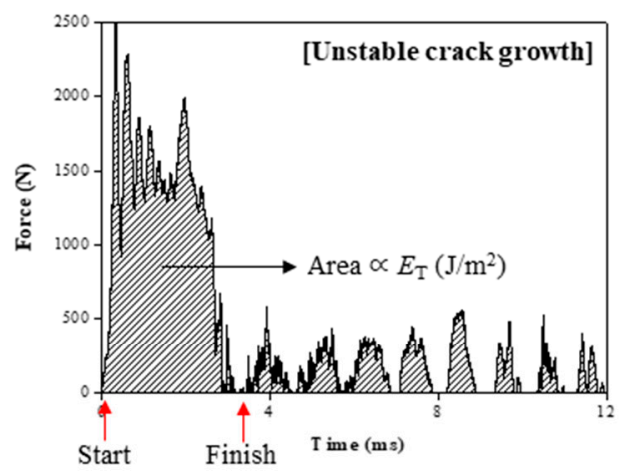

(b)

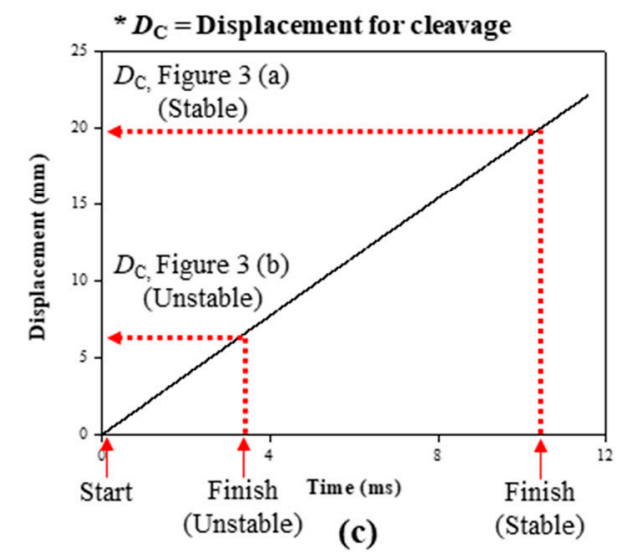

Figure 3. Results of impact wedge-peel test: Time-force curves for (a) stable crack growth and (b) unstable crack growth. (c) Time-displacement curve.

\section{Results and Discussion}

\subsection{Curing Behavior of CSR/Epoxy Composite}

The curing behavior of the CSR/epoxy composite was studied by DSC (Figure 4). As the curing of epoxy is an exothermic reaction, all the samples exhibited an exothermic peak, and the maximum temperature of heat flow ( $T_{\max (\text { heat flow) }}$ ) was plotted as a function of CSR content. Notably, as the CSR content increased, $T_{\max }$ (heat flow) got higher. This indicates that the addition of CSR particles retarded the curing reaction of epoxy due to the steric hindrance effect of the CSR particles in the CSR/epoxy composite. 

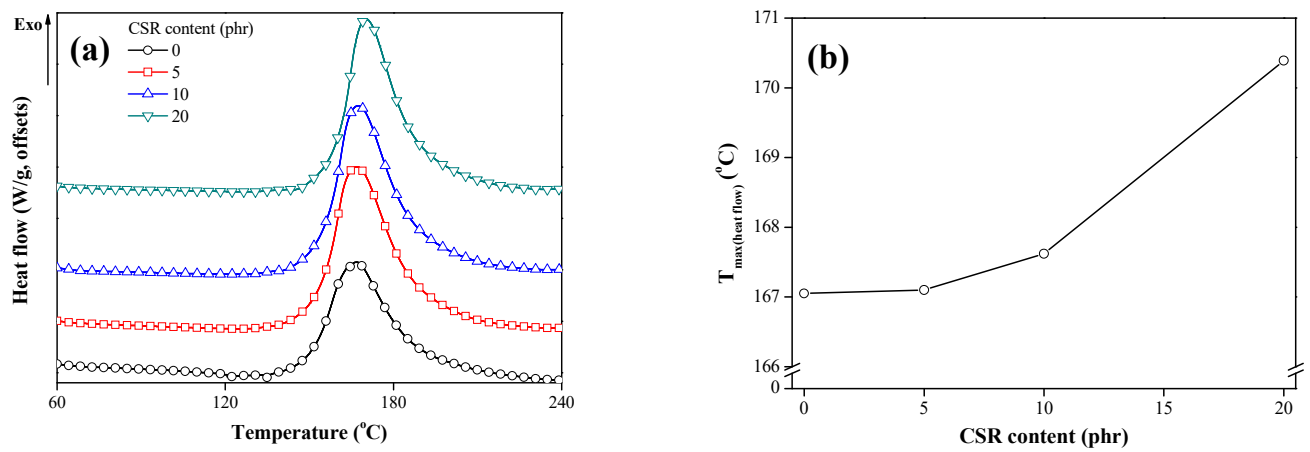

Figure 4. (a) Differential scanning calorimetry (DSC) curves of CSR/epoxy composites and (b) maximum temperature of heat flow.

\subsection{Pore Structure of CSR/Epoxy Composite Foam Adhesive}

The pore structures of the CSR/epoxy composite foam adhesives were analyzed by X-ray CT. As shown in Figure 5, the pore structure could be investigated from the 3D images of the CSR/epoxy composite foam adhesives, where the pore sizes are assigned a color gradation. Notably, the pore size changed with the CSR content, which indicated that the addition of CSR particles affected the expansion of the foaming agent. To quantitatively compare the pore structures of the CSR/epoxy composite foam adhesives, many parameters, including the average pore size, standard deviation of pore size, porosity, and expansion ratio, were evaluated (Figure 6). The pore size and expansion ratio for $1 \mathrm{phr}$ foaming agent is higher than those for $0.1 \mathrm{phr}$ foaming agent. Compared to $0 \mathrm{phr}$ CSR content, at 5 and $10 \mathrm{phr}$ CSR contents, the pore size and expansion ratio increased sufficiently due to the decrease in curing rate. It has been reported that the curing behavior affects the pore growth and that the expansion ratio increases at a slow curing speed $[1,14]$. However, although curing was retarded at $20 \mathrm{phr}$ CSR content, the pore size and expansion ratio decreased. This might have resulted from the steric hindrance effect of the CSR particles, which spatially prevented the expansion of the foaming agent [1]. 


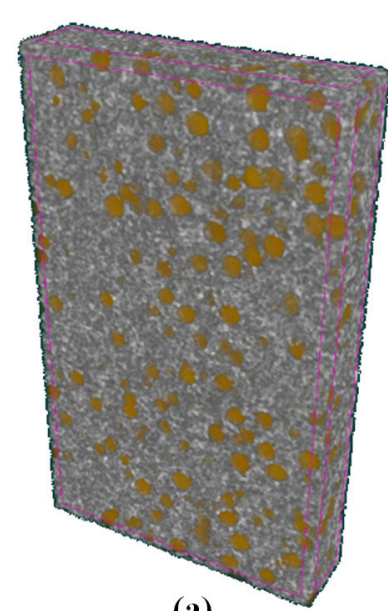

(a)

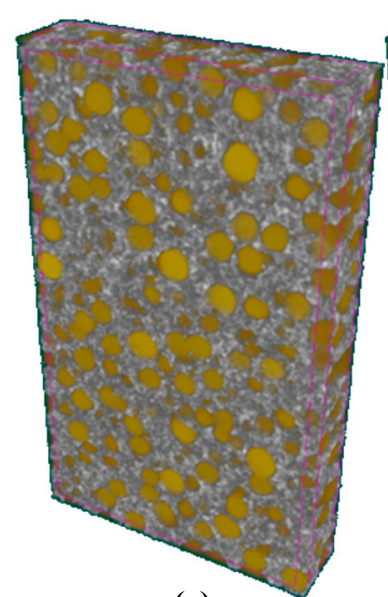

(e)

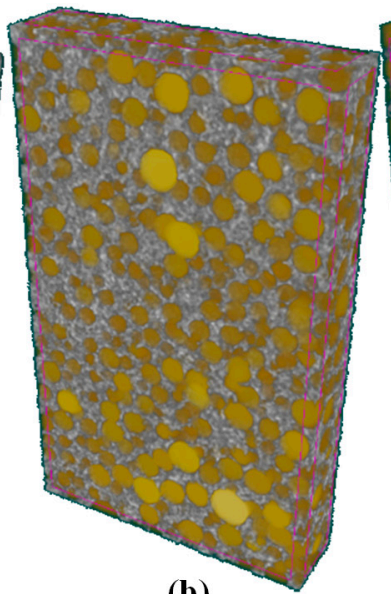

(b)

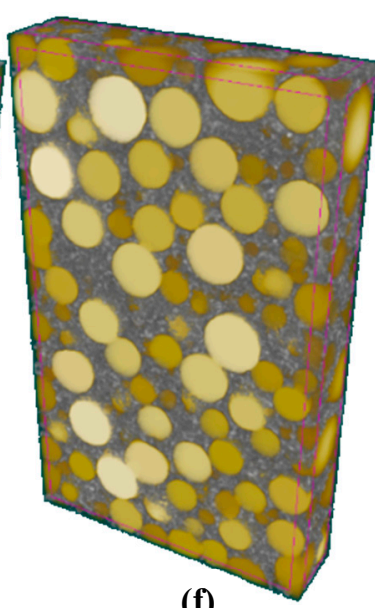

(f)

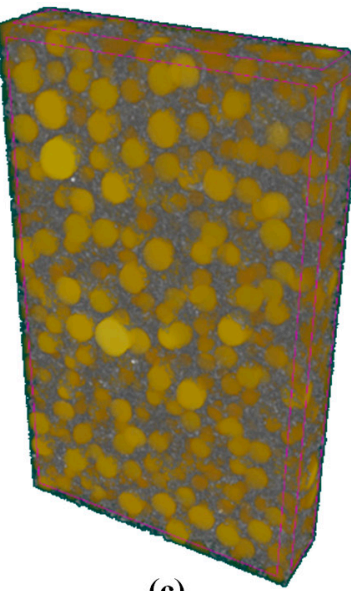

(c)

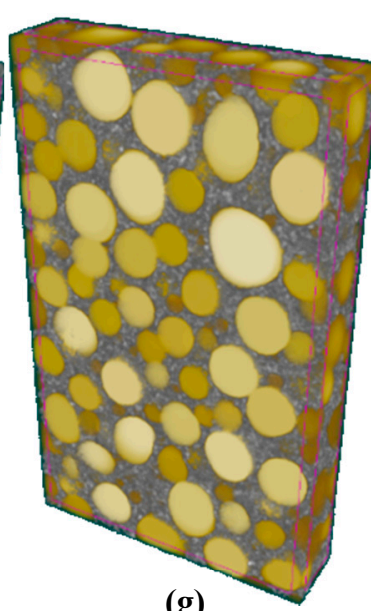

(g)

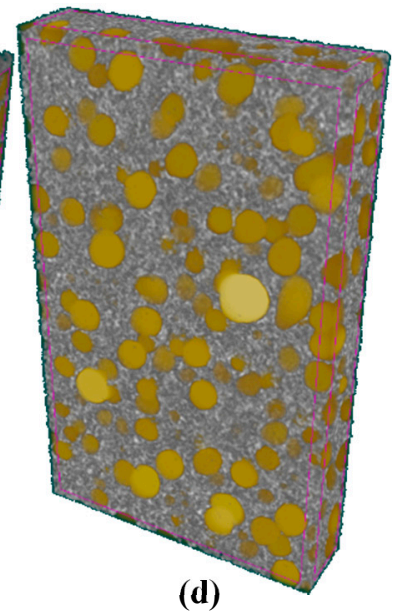

(d)

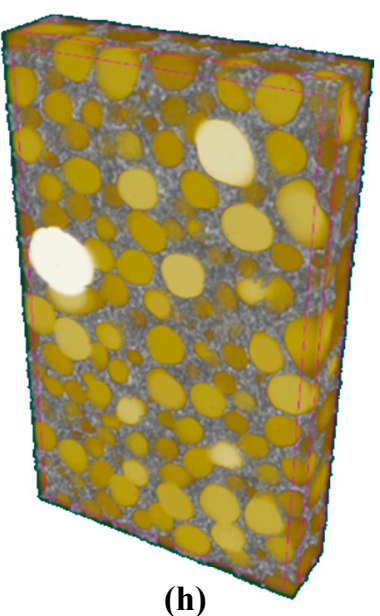

(h)

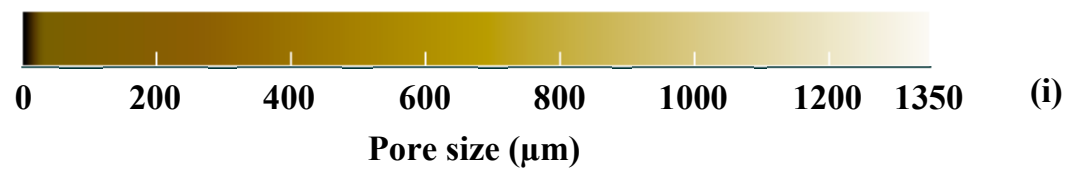

Figure 5. 3D images of CSR/epoxy composite foam adhesives: (a) CSR 0/FA 0.1, (b) CSR 5/FA 0.1, (c) CSR 10/FA 0.1, (d) CSR 20/FA 0.1, (e) CSR 0/FA 1, (f) CSR 5/FA 1, (g) CSR 10/FA 1, and (h) CSR 20/FA 1. (i) Color scale indicator for pore size (FA = Foaming agent). 

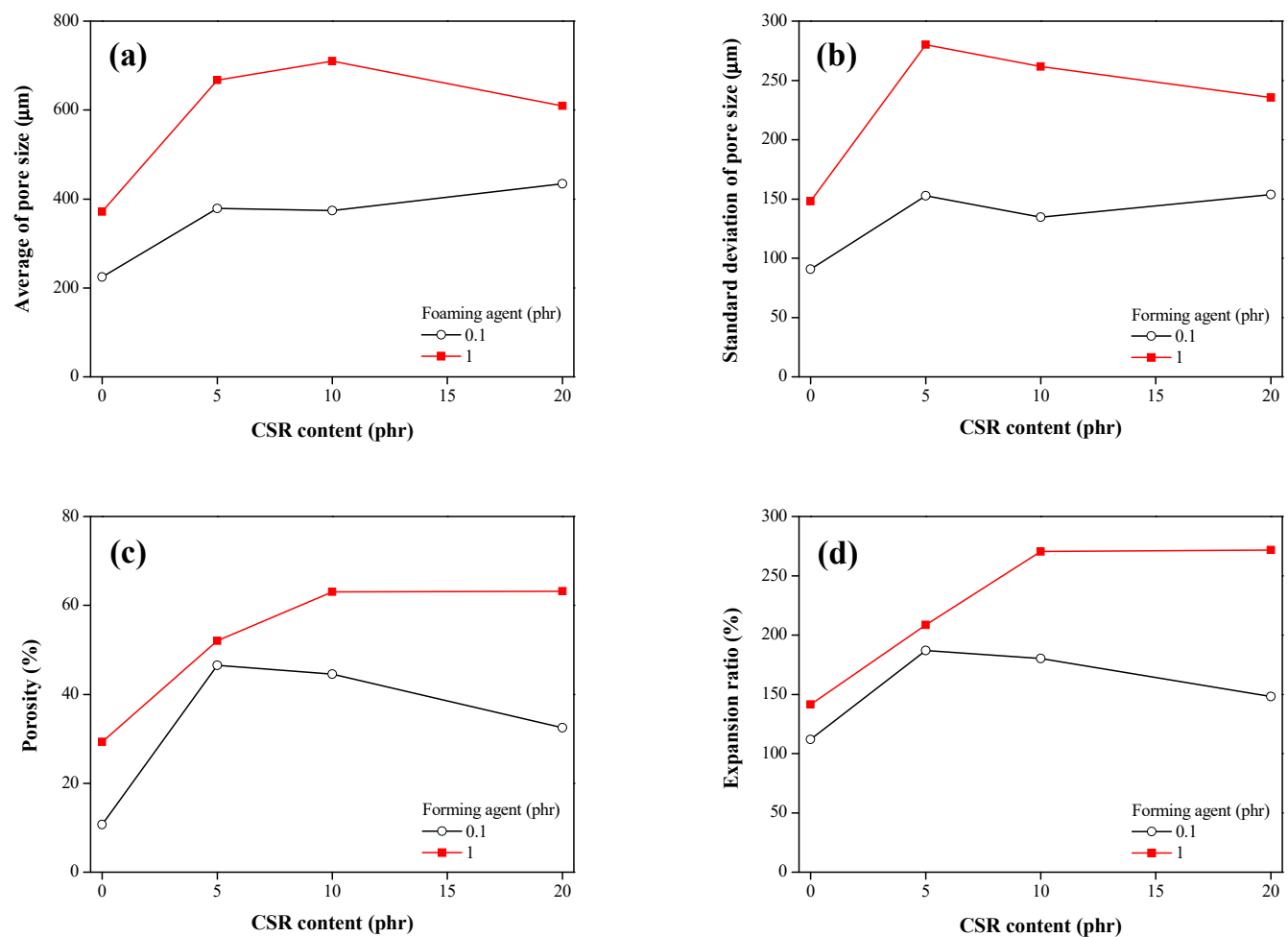

Figure 6. (a) Average and (b) standard deviation of pore size, (c) porosity, and (d) expansion ratio of CSR/epoxy composite foam adhesives.

\subsection{Resistance to Cleavage of Adhesive under Impact Wedge-Peel Condition}

Under the impact wedge-peel condition, the impact force was measured for $20 \mathrm{~ms}$ (Figure 7). With an increase in CSR content, the force was increased and sustained for a longer period, indicating that the CSR particles significantly improved the impact resistance of the epoxy composite foam adhesives. On the other hand, as the foaming agent content increased, the cleavage time decreased drastically, suggesting that the CSR/epoxy composite foam adhesive became fragile.

As shown in Table 3, the type of crack growth and the displacement for cleavage were investigated to compare the impact resistance. With an increase in the foaming agent content, the CSR/epoxy composite foam adhesives exhibited unstable crack growth and a short displacement for cleavage $\left(D_{C}\right)$. It indicates that the impact resistance deteriorated with increasing foaming agent content. As the CSR content increased, the impact resistance of the CSR/epoxy composite foam adhesive improved dramatically, resulting in an increase in $D_{\mathrm{C}}$ and changing the type of crack growth from unstable to stable crack growth.

Additionally, by comparing the energy for crack growth $\left(E_{\mathrm{C}}\right)$, we quantitatively evaluated the resistance to cleavage of the CSR/epoxy composite foam adhesives under the impact wedge-peel condition. As shown in Figure 8, at foaming agent contents of 0 and $0.1 \mathrm{phr}$, the $E_{\mathrm{C}}$ was significantly enhanced by the addition of CSR particles, indicating an improvement in impact resistance. However, as the foaming agent content increased to $1 \mathrm{phr}$, the $E_{\mathrm{C}}$ hardly increased, which suggests that the impact resistance effectively improved at low foaming agent contents ( 0 and $0.1 \mathrm{phr}$ ). 

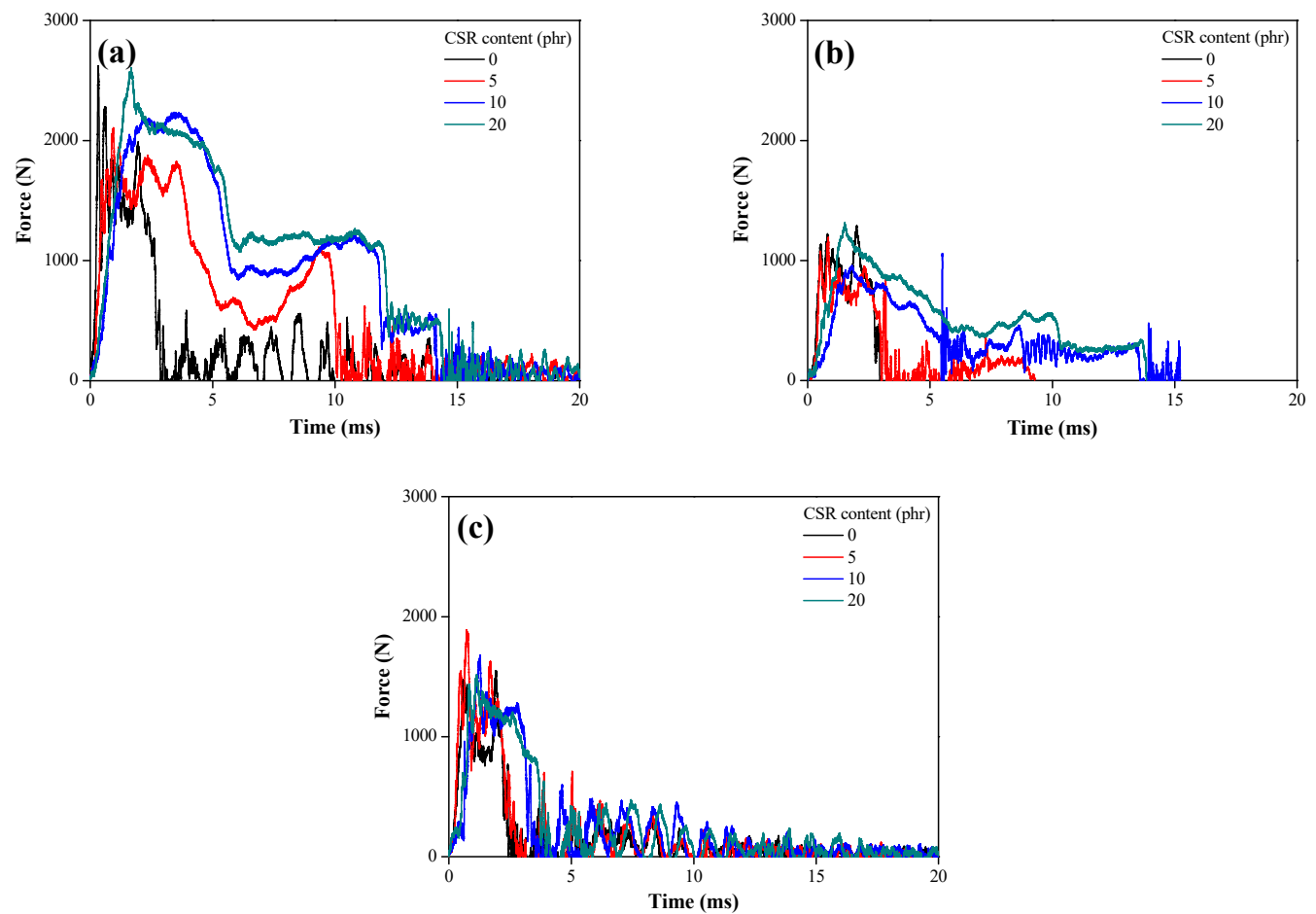

Figure 7. Time-force curves of impact wedge-peel test: Foaming agent content of (a) 0 phr, (b) $0.1 \mathrm{phr}$, and (c) 1 phr.

Table 3. Type of crack growth and displacement for cleavage of CSR/epoxy composite foam adhesives.

\begin{tabular}{|c|c|c|c|}
\hline Foaming Agent Content (phr) & CSR Content (phr) & Type of Crack Growth & ${ }^{*} D_{\mathrm{C}}(\mathrm{mm})$ \\
\hline \multirow{4}{*}{0} & 0 & Unstable & $9.94( \pm 7.16)$ \\
\hline & 5 & Unstable/Stable & $22.11( \pm 5.17)$ \\
\hline & 10 & Stable & $26.30( \pm 1.15)$ \\
\hline & 20 & Stable & $26.57( \pm 0.93)$ \\
\hline \multirow{4}{*}{0.1} & 0 & Unstable & $9.23( \pm 5.53)$ \\
\hline & 5 & Unstable & $10.88( \pm 6.34)$ \\
\hline & 10 & Unstable/Stable & $22.40( \pm 7.81)$ \\
\hline & 20 & Stable & $28.87( \pm 0.55)$ \\
\hline \multirow{4}{*}{1} & 0 & Unstable & $5.85( \pm 1.22)$ \\
\hline & 5 & Unstable & $7.29( \pm 2.23)$ \\
\hline & 10 & Unstable & $8.45( \pm 1.63)$ \\
\hline & 20 & Unstable & $13.27( \pm 4.46)$ \\
\hline
\end{tabular}

${ }^{*} D_{\mathrm{C}}=$ Displacement for cleavage.

Notably, for the CSR/epoxy composite foam adhesive containing $0.1 \mathrm{phr}$ foaming agent and $20 \mathrm{phr}$ CSR particles, the $E_{\mathrm{C}}\left(34,000 \mathrm{~J} / \mathrm{m}^{2}\right)$ was more than two times that of the adhesive containing no CSR particle $\left(12,000 \mathrm{~J} / \mathrm{m}^{2}\right)$. In addition, the type of crack growth changed from unstable to stable crack propagation by the addition of $20 \mathrm{phr}$ CSR particles into the sample containing $0.1 \mathrm{phr}$ foaming agent. Moreover, the expansion ratio of the adhesive containing $0.1 \mathrm{phr}$ foaming agent and $20 \mathrm{phr}$ CSR particles increased, compared to the adhesive containing no CSR particle; this indicated that a simultaneous increase in both the expansion ratio $(\sim 148 \%)$ and impact resistance was achieved. 


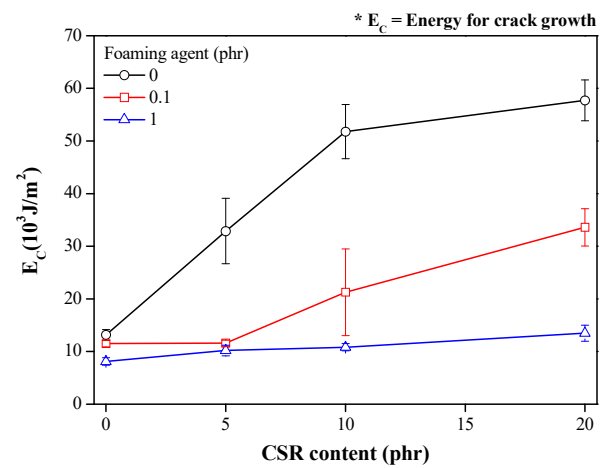

Figure 8. Energy for crack growth of CSR/epoxy composite foam adhesives.

\section{Conclusions}

CSR/epoxy composite foam adhesives were prepared with different amounts of foaming agent and CSR particles. With increasing CSR content, the curing reaction retarded, which affected the growth of the pores. The pore structure, pore size, porosity, and expansion ratio were determined by X-ray CT. The expansion ratio for $1 \mathrm{phr}$ foaming agent was higher than that for $0.1 \mathrm{phr}$ foaming agent. At 5 and $10 \mathrm{phr}$ CSR content, the pore size and expansion ratio increased by decrease in curing rate, but, at $20 \mathrm{phr}$ CSR content, the pore size and expansion ratio decreased due to the steric hindrance effect of the CSR particles. The impact resistance of the CSR/epoxy composite foam adhesive was compared in terms of $E_{C}$. It was significantly enhanced by the addition of CSR particles at 0 and $0.1 \mathrm{phr}$ foaming agent. However, at $1 \mathrm{phr}$ foaming agent, the $E_{\mathrm{C}}$ was hardly improved by the addition of CSR particle, indicating that the improvement in impact resistance is effective only at low foaming agent contents $(0$ and $0.1 \mathrm{phr}$ ). For the CSR/epoxy composite foam adhesives containing $0.1 \mathrm{phr}$ foaming agent and 20 phr CSR particles, a simultaneous increase in both the expansion ratio $(\sim 148 \%)$ and impact resistance $\left(E_{\mathrm{C}}=34000 \mathrm{~mJ} / \mathrm{cm}^{2}\right)$ was achieved. A limitation of this study is that we only focused on the impact resistance of the CSR-epoxy composite foam adhesives at room temperature. Since CSR particles can improve impact resistance at low temperatures, it is necessary to investigate the impact resistance of CSR/epoxy composite foam adhesives at low temperatures in future research.

Author Contributions: Conceptualization, investigation, writing-original draft, writing-review and editing J.-H.B.; Writing-review and editing, D.B. and J.-H.S.; supervision, S.-W.J. and H.-J.K.; methodology, J.-H.K., H.-K.S., and M.-J.Y.; resources, J.-W.H.

Funding: This work was supported by the World Class 300 Project (R\&D) [grant number S2483588, Development of high-performance adhesives for weight reduction of automotive] of the SMBA (Korea).

Conflicts of Interest: The authors declare no conflict of interest.

\section{References}

1. Back, J.-H.; Hwang, J.-U.; Lee, Y.-H.; Baek, D.; Park, J.-W.; Kim, H.-J.; Kim, J.-H.; Song, H.-K.; Yoo, M.-J. Morphological study and mechanical property of epoxy-foam adhesives based on epoxy composites for automotive applications. Int. J. Adhes. Adhes. 2018, 87, 124-129. [CrossRef]

2. Stroganov, V. Epoxy-foam adhesives. Polym. Sci. Ser. D 2013, 6, 275-279. [CrossRef]

3. Wang, L.; Yang, X.; Zhang, J.; Zhang, C.; He, L. The compressive properties of expandable microspheres/epoxy foams. Compos. Part B Eng. 2014, 56, 724-732. [CrossRef]

4. Kadioglu, F.; Adams, R.D. Flexible adhesives for automotive application under impact loading. Int. J. Adhes. Adhes. 2015, 56, 73-78. [CrossRef]

5. Kim, J.-K.; Mackay, D.; Mai, Y.-W. Drop-weight impact damage tolerance of CFRP with rubber-modified epoxy matrix. Composites 1993, 24, 485-494. [CrossRef]

6. Ratna, D.; Banthia, A.; Deb, P. Acrylate-based liquid rubber as impact modifier for epoxy resin. J. Appl. Polym. Sci. 2001, 80, 1792-1801. [CrossRef] 
7. Zhou, H.; Xu, S. A new method to prepare rubber toughened epoxy with high modulus and high impact strength. Mater. Lett. 2014, 121, 238-240. [CrossRef]

8. Singh, K.; Nanda, T.; Mehta, R. Addition of nanoclay and compatibilized EPDM rubber for improved impact strength of epoxy glass fiber composites. Compos. Part A Appl. Sci. Manuf. 2017, 103, 263-271. [CrossRef]

9. Memon, N.A. Rheological properties and the interface in polycarbonate/impact modifier blends: Effect of modifier shell molecular weight. J. Polym. Sci. Part B Polym. Phys. 1998, 36, 1095-1105. [CrossRef]

10. Bain, E.D.; Knorr, D.B.; Richardson, A.D.; Masser, K.A.; Yu, J.; Lenhart, J.L. Failure processes governing high-rate impact resistance of epoxy resins filled with core-shell rubber nanoparticles. J. Mater. Sci. 2016, 51, 2347-2370. [CrossRef]

11. Gao, G.; Zhou, C.; Yang, H.; Zhang, H. Influence of core-shell rubber particles synthesized with different initiation systems on the impact toughness of modified polystyrene. J. Appl. Polym. Sci. 2007, 103, 738-744. [CrossRef]

12. Ren, Q.; $\mathrm{Xu}, \mathrm{H}$.; $\mathrm{Yu}, \mathrm{Q}$; $\mathrm{Zhu}, \mathrm{S}$. Development of epoxy foaming with $\mathrm{CO}_{2}$ as latent blowing agent and principle in selection of amine curing agent. Ind. Eng. Chem. Res. 2015, 54, 11056-11064. [CrossRef]

13. Stefani, P.; Cyras, V.; Tejeira Barchi, A.; Vazquez, A. Mechanical properties and thermal stability of rice husk ash filled epoxy foams. J. Appl. Polym. Sci. 2006, 99, 2957-2965. [CrossRef]

14. Takiguchi, O.; Ishikawa, D.; Sugimoto, M.; Taniguchi, T.; Koyama, K. Effect of rheological behavior of epoxy during precuring on foaming. J. Appl. Polym. Sci. 2008, 110, 657-662. [CrossRef]

15. Chen, K.; Tian, C.; Lu, A.; Zhou, Q.; Jia, X.; Wang, J. Effect of $\mathrm{SiO}_{2}$ on rheology, morphology, thermal, and mechanical properties of high thermal stable epoxy foam. J. Appl. Polym. Sci. 2014, 131, 40068.

16. Patterson, B.M.; Henderson, K.; Smith, Z. Measure of morphological and performance properties in polymeric silicone foams by X-ray tomography. J. Mater. Sci. 2013, 48, 1986-1996. [CrossRef]

17. Awaja, F.; Arhatari, B.; Wiesauer, K.; Leiss, E.; Stifter, D. An investigation of the accelerated thermal degradation of different epoxy resin composites using X-ray microcomputed tomography and optical coherence tomography. Polym. Degrad. Stab. 2009, 94, 1814-1824. [CrossRef]

18. Khalili, S.; Shokuhfar, A.; Hoseini, S.; Bidkhori, M.; Khalili, S.; Mittal, R. Experimental study of the influence of adhesive reinforcement in lap joints for composite structures subjected to mechanical loads. Int. J. Adhes. Adhes. 2008, 28, 436-444. [CrossRef]

19. Blackman, B.; Kinloch, A.; Taylor, A.; Wang, Y. The impact wedge-peel performance of structural adhesives. J. Mater. Sci. 2000, 35, 1867-1884. [CrossRef]

20. Taylor, A.; Williams, J. Determining the fracture energy of structural adhesives from wedge-peel tests. J. Adhes. 2011, 87, 482-503. [CrossRef]

21. Blackman, B.; Kinloch, A.; Sanchez, F.R.; Teo, W.; Williams, J. The fracture behaviour of structural adhesives under high rates of testing. Eng. Fract. Mech. 2009, 76, 2868-2889. [CrossRef] 